\title{
Codon optimization, expression, purification, and functional characterization of recombinant human IL-25 in Pichia pastoris
}

\author{
Yushan Liu • Chengsheng Wu • Jinyu Wang • Wei Mo • \\ Min Yu
}

Received: 3 July 2013 /Revised: 12 September 2013 / Accepted: 14 September 2013 / Published online: 8 October 2013

(C) The Author(s) 2013. This article is published with open access at Springerlink.com

\begin{abstract}
Interleukin (IL)-25 (also known as IL-17E) is a distinct member of the IL-17 cytokine family which induces IL-4, IL-5, and IL-13 expression and promotes pathogenic T helper (Th)-2 cell responses in various organs. IL-25 has been shown to have crucial role between innate and adaptive immunity and also a key component of the protection of gastrointestinal helminthes. In this study, to produce bioactive recombinant human IL-25 (rhIL-25), the cDNA of mature IL-25 was performed codon optimization based on methylotropic yeast Pichia pastoris codon bias and cloned into the expression vector $\mathrm{pPICZ} \alpha \mathrm{A}$. The recombinant vector was transformed into P. pichia strain X-33 and selected by zeocin resistance. Benchtop fermentation and simple purification strategy were established to purify the rhIL-25 with about $17 \mathrm{kDa}$ molecular mass. Functional analysis showed that purified rhIL-25 specifically bond to receptor IL-17BR and induce G-CSF production in vitro. Further annexin V-FITC/PI staining assay indicated that rhIL-25 induced apoptosis in two breast cancer cells, MDA-MB-231 and HBL-100. This study provides a new strategy for the large-scale production of bioactive IL-25 for biological and therapeutic applications.
\end{abstract}

Keywords IL-25 - Pichia pastoris · Codon optimization · Functional characterization $\cdot$ Apoptosis

\section{Introduction}

Interleukin-25(IL-25), also known as IL-17E, is the most distinct member of the IL-17 cytokine family. Originally identified

Y. Liu $\cdot$ C. Wu $\cdot$ J. Wang $\cdot$ W. Mo $\cdot$ M. Yu $(\bowtie)$

Key Laboratory of Molecular Medicine, Ministry of Education, Department of Biochemistry and Molecular Biology,

Shanghai Medical College, Fudan University,

Room 111, Building 13, No. 130 Dong'an Road,

Xuhui District, Shanghai 200032, People's Republic of China

e-mail: minyu@shmu.edu.cn as homology to IL-17 family members (Fort et al. 2001; Lee et al. 2001), IL-25 was initially found to accumulate in polarized Th2 cells (Fort et al. 2001). Related studies also demonstrated that other cell types from hematopoietic or nonhematopoietic compartments could produce IL- 25 under certain circumstances, such as primary bone marrow-derived mast cells upon IgE cross-linking (Ikeda et al. 2003), eosinophils and basophiles upon stem cell factor stimulation (Dolgachev et al. 2009; Wang et al. 2007), lung epithelial cells upon allergic response (Angkasekwinai et al. 2007), and alveolar macrophages after particle inhalation (Kang et al. 2005). The accumulation of IL-25 could also be seen in intestinal epithelial cells and brain capillary endothelial cells (Sonobe et al. 2009; Zaph et al. 2008). Many investigations confirmed the ability of different cell types to produce IL-25, while the mechanisms to control IL-25 production remain unclear.

IL-25 share the same receptor with IL-17B, named IL17RB, IL-17BR, or Evi27, which was also identified based on sequence similarity to the IL-17 receptor. However, IL-25 has higher binding affinity to IL-17RB compared to that of IL17B (Lee et al. 2001; Shi et al. 2000; Tian et al. 2000). Further study showed that IL-17RA and IL-17RB are both required for activating signals in response to IL-25, although IL-25 did not bind to IL-17RA (Rickel et al. 2008). Currently, the downstream targets of IL-25 signaling pathway still remain unclear.

As a distinct cytokine of the IL-17 family, IL-25 has the least structural homology with the prototypical IL-17 family member, IL-17A, which indicated why its biologic activities are distinct from other IL-17 family members. The cytokines of IL-17 family, not IL-25, induce the production of proinflammatory cytokines and play similar roles in the development of certain diseases. Alternatively, IL-25 has its unique abilities in regulating Th2 cell-type immune responses. It also plays a decisive role both in the induction of a protective response against parasites and in the initiation of innate and adaptive pro-allergic responses (Monteleone et al. 2010). It is interesting that IL-25 was also involved in anti-tumor (Benatar et al. 2008, 
2010) and anti-inflammatory activities based on various studies of human and animal models (Mchenga et al. 2008).

Until now, the recombinant human IL-25 (rhIL-25) is transiently produced using recombinant adenovirus or expressed in cell lines including human embryonic kidney (HEK) 293 cells or Sf9 insect cells on a small scale (Fort et al. 2001; Hurst et al. 2002). Commercial rhIL-25 is generated from an Escherichia coli expression system which may involve proper fold problem. In this study, using a eukaryotic expression system of $P$. pastoris, we established a more efficient and cost-effective method to produce functional rhIL-25 in large quantities. This will facilitate further study of its mechanisms in the pathogenesis of immune diseases, the structure-function relationship, and possible clinical applications.

\section{Materials and methods}

Strains and reagents

P. pastoris strain $\mathrm{X}-33$, expression vector $\mathrm{pPICZ} \alpha \mathrm{A}$, and antibiotic zeocin were products from Invitrogen (USA). Mouse anti-human IL-25 monoclonal antibody and E. coliderived rhIL-25 were purchased from R\&D (USA). Restriction enzymes were products of New England Biolabs (USA). Primers were synthesized by Sangon Biological Co., Ltd. (Shanghai, China). Other reagents were obtained from standard commercial sources and were of reagent grade.

Synthesis of human $I L-25$ gene and construction of expression vector

To improve the production of recombinant hIL-25 in $P$. pastoris, we carried out a codon optimization of the $h I L-25$ gene and constructed an artificial gene according to the specific codon usage of $P$. pastoris (codon usage database from http://www.kazusa.or.jp/codon). We designed a cloning approach based on synthetic overlapping primers and a PCR assembly strategy to construct a synthetic $h I L-25 \mathrm{cDNA}$ fragment without the signal peptide sequence (Xiong et al. 2004). The $h I L-25$ cDNA (GenBank accession number BC069565) was used as template for optimization to generate a set of ten overlapping oligonucleotides (as showed in Table 1), of which $\mathrm{G}+\mathrm{C}$ content was adjusted to meet codon preference. A mixture of the oligonucleotides (10 ng each) was used in a first-round ten cycles of PCR procedure using $p f u$ polymerase to generate most sections of the coding sequence. Then, the region for Xho I restriction site and Kex2 and Ste13 cleavage sites of $\alpha$-factor signal sequence of $P$. pastoris were added to the $5^{\prime}$ terminal of the synthesized fragment in the second-round PCR using the most $5^{\prime}$ end primer N1 (see Table 1). At the same time, Not I restriction site was linked to the 3 '-terminal using the most 3 ' end primer
C1. The complete artificial DNA was first cloned into the Xho I-NotI frame of vector pBluescript SK and confirmed by automated DNA sequencing. Then, the certified fragment was directly cloned into pPICZ $\alpha \mathrm{A}$, in-frame with the $\alpha$-factor signal sequence under the control of the $A O X 1$ promoter. The $\mathrm{C}$-terminal stop codon to terminate translation is immediate after the last amino acid of hIL-25.

\section{Transformation of $P$. pastoris and screening}

Yeast transformation was performed on an electroporation system (Bio-Rad, USA) according to the manufacturer's instruction. The recombinant vector pPICZ $\alpha \mathrm{A}-h I L-25$ was linearized with $\mathrm{Sac}$ I and electroporated into competent $P$. pastoris strain X-33. The electroporated mixture was spread on YPDS plates ( $1 \%$ yeast extract, $2 \%$ peptone, $2 \%$ glucose, $1 \mathrm{~mol} / \mathrm{l}$ sorbitol, $2 \%$ agar) containing $100 \mu \mathrm{g} / \mathrm{ml}, 500 \mu \mathrm{g} / \mathrm{ml}$, $1 \mathrm{mg} / \mathrm{ml}$, or $2 \mathrm{mg} / \mathrm{ml}$ zeocin, respectively, for growth selection. After $72 \mathrm{~h}$ of incubation at $30^{\circ} \mathrm{C}$, the positive colonies were certified for integration of $h I L-25$ gene into the Pichia genome by PCR using the primers of $5^{\prime} A O X, 3^{\prime} A O X$, and IL25 gene-specific primers. The confirmed transformants were kept for further analysis.

Shake flask expression screening of rhIL-25 expression stain

The positive transformants were tested for their ability to secret rhIL-25 into the culture medium. Five milliliters of MGYH medium (1.34\% YNB, $1 \%$ glycerol, $4 \times 10^{-5} \%$ biotin, $0.004 \%$ histidine) of shake flask cultures from the $P$. pastoris clones ( $h I L-25 / \mathrm{X}-33$ clones) was grown overnight at $30{ }^{\circ} \mathrm{C}$ in $25-\mathrm{ml}$ baffled flasks $(250 \mathrm{rpm})$ to an $\mathrm{OD}_{600}$ between 2 and 6 . The cultures were centrifuged for $5 \mathrm{~min}$ at $3,000 \mathrm{~g}$. The pellets were then transferred to $20 \mathrm{ml}$ of MMH $(1.34 \%$ YNB, $4 \times 10^{-5} \%$ biotin, $0.5 \%$ methanol, $0.004 \%$ histidine) medium to culture at $\mathrm{OD}_{600}$ of 1.0 in $100-\mathrm{ml}$ baffled flasks to induce expression at $30^{\circ} \mathrm{C}$. In each of the following 4 days, pure methanol was added to the culture to a final concentration of $1 \%(v / v)$, while $200 \mu \mathrm{l}$ of cell culture was collected and centrifuged at $12,000 \mathrm{~g}$ for $5 \mathrm{~min}$ at $4{ }^{\circ} \mathrm{C}$. Supernatants were collected to monitor the expression and secretion of rhIL-25 by SDS-PAGE separation, followed by Coomassie blue stain.

Bench-scale fermentation and purification procedure

Fermentations were performed in a 5-1 working volume bioreactor (Bioflo 3000, New Brunswick Scientific, USA) according to Invitrogen instructions for $P$. pastoris fermentation. Two liters of basal salts medium $(4.25 \mathrm{ml} / 1$ orthophosphoric acid,

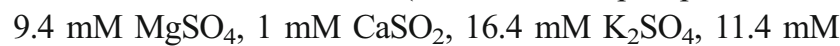
$\mathrm{KOH}$, and $50 \mathrm{ml} / 1$ glycerol) was sterilized in the bioreactor. Ammonium was used as both a $\mathrm{pH}$ control reagent and a nitrogen source. PTM1 trace salts $(2 \mathrm{ml} / \mathrm{l} ; 24 \mathrm{mM} \mathrm{CuSO}$, 
Table 1 Primers used for the synthesis of optimized $h I L-25$ gene

\begin{tabular}{llll}
\hline Primer & Oligonucleotide sequences $\left(5^{\prime}-3^{\prime}\right)^{\mathrm{a}}$ & Orientation \\
\hline F1A & TACTCTCATTGGCCATCTTGTTGTCCATCTAAGGGTCAAGACACCTCTGAAGAATTGTTG & Sense \\
R2B & TAGCTGGTTCTAAAGGTGGAACTGGAACAGTAGACCATCTCAACAATTCTTCAGAGGTGT & Anti-sense \\
F3C & TCCACCTTTAGAACCAGCTAGACCAAACAGACATCCAGAATCTTGTAGAGCTTCTGAAGA & Sense & Anti-sense \\
R4D & GTATCTCCAAGGAGAAATAGCTCTGGAGTTAAGTGGACCATCTTCAGAAGCTCTACAAGA & Sense \\
F5E & CTATTTCTCCTTGGAGATACGAATTGGATAGAGATTTGAACAGATTGCCACAAGATTTGT & Anti-sense \\
R6F & TGCAAAGAAACACAATGTGGACACAAACATCTAGCATGGTACAAATCTTGTGGCAATCTG & Sense \\
F7G & CCACATTGTGTTTCTTTGCAAACTGGTTCTCATATGGACCCAAGAGGTAACTCTGAATTG & Anti-sense \\
R8H & GACATGGTCTTCTGTAGAAGACAGTTTGGTTATGGTACAACAATTCAGAGTTACCTCTTG & Sense \\
F9I & CTTCTACAGAAGACCATGTCATGGTGAAAAGGGTACTCATAAGGGTTACTGTTTGGAAAG & Anti-sense \\
R10J & TCTAACACAAACACAAGCCAAAGAAACTCTGTACAATCTTCTTTCCAAACAGTAACCCTT & Sense \\
N1 & TCTCTCGAGAAAAGAGAGGCTGAAGCTTACTCTCATTGGCCATCTTG & Anti-sense \\
C1 & ATATTTTAGCGGCCGCTTAACCCATAACTCTTGGTCTAACACAAACACAAGCCA & \\
\hline
\end{tabular}

${ }^{\mathrm{a}}$ Sequences added to introduce restriction endonuclease recognition sites (Xho I and Not $\left.\mathrm{I}\right)$ are italicized

$0.53 \mathrm{mM} \mathrm{NaI}, 19.87 \mathrm{mM} \mathrm{MnSO}_{4}$, and $0.83 \mathrm{mM} \mathrm{Na}_{2} \mathrm{MoO}_{4}$, $0.32 \mathrm{mM}$ boric acid, $2.1 \mathrm{mM} \mathrm{CoCl}_{2}, 0.15 \mathrm{mM} \mathrm{ZnCl}_{2}, 0.23 \mathrm{M}$ $\mathrm{FeSO}_{4}$, and $0.82 \mathrm{mM}$ biotin) were added after sterilization. The certified rhIL-25 producing $P$. pastoris strain was grown as seed broth in $200 \mathrm{ml}$ of BMGY ( $2 \%$ peptone, $1 \%$ yeast extract, $100 \mathrm{~mm}$ potassium phosphate, $\mathrm{pH} 6.0,1.34 \%$ yeast nitrogen base (without amino acid), $0.4 \mu \mathrm{g} / \mathrm{ml}$ biotin, $1 \%$ glycerol) overnight till $\mathrm{OD}_{260}$ reached 4 and then inoculated into $2.0 \mathrm{~L}$ basal salts medium in a fermentor.

Throughout the fermentation process, temperature, dissolved oxygen (DO) concentration, and $\mathrm{pH}$ were monitored and maintained at set points of $30{ }^{\circ} \mathrm{C}, 30 \%$ and 5.0 , respectively. DO concentration was maintained above $30 \%$ by enriching the inlet air with pure oxygen passing through a mass flow controller when needed. A glycerol-fed-batch phase was carried out in which biomass was bulked up to the desired cell density using $50 \%$ glycerol feed containing 12 ml/1 PTM1 trace salt. The exhaustion of glycerol was indicated by a spike in the DO, which happened 24-26 h after inoculation to the OD value at $600 \mathrm{~nm}$ reached around 100-120. After the growth phase on glycerol was finished, induction was carried out by feeding methanol (containing $12 \mathrm{ml} / 1$ PTM1) at a gradient feed rate into the fermentor.

The induction phase was maintained for $44 \mathrm{~h}$, and then the culture medium was centrifuged at $8,000 \mathrm{~g}$ for $30 \mathrm{~min}$ at $4{ }^{\circ} \mathrm{C}$. The supernatant was clarified by a bacterial filter $(0.45 \mu \mathrm{m})$ and concentrated by ultrafiltration using a Pellicon cassette (Millipore, USA) with a molecular cutoff of 1,000 Da. The retention liquid was then run a buffer exchange against $50 \mathrm{mM}$ Tris-Cl, 1 mM EDTA (pH 8.8), and loaded onto Q sepharose Fast Flow anion-exchange resin (GE healthcare, USA) equilibrated by the same buffer. The flow-through, which contained rhIL-25, was collected and further depurated through a gel filtration chromatography medium Sephacryl S-100 High Resolution (GE healthcare, USA) balanced with $20 \mathrm{mM}$ PB
(pH7.4). Fractions of purified rhIL-25 were lyophilized after the addition of trehalose to a final concentration of $15 \%$.

\section{SDS-PAGE and western blot analysis}

Protein samples were separated on $15 \%$ SDS-PAGE gels and stained with sliver or Coomassie Blue R-250. To characterize the recombinant hIL-25, samples were also electroblotted onto PVDF membrane (Millipore,USA) using Mini Trans-Blot ${ }^{\circledR}$ Cell (Bio-Rad, USA) according to the manufacturer's instructions. The membrane was blocked with $5 \%$ milk in TBST (10 M Tris- $\mathrm{HCl}, 150 \mathrm{mM} \mathrm{NaCl}, \mathrm{pH} 8.0$, and $0.1 \%$ Tween 20 ) for $2 \mathrm{~h}$ at room temperature. The membrane was then incubated for $2 \mathrm{~h}$ at room temperature with mouse anti-hIL-25 monoclonal antibody (R\&D,USA). After washing four times with TBST, the membrane was incubated for $1 \mathrm{~h}$ with peroxidase-conjugated goat anti-mouse IgG (R\&D, USA). The membrane was washed three times with TBST, and the blot was visualized by chemiluminescence via the Pierce SuperSignal ECL detection kit (Pierce, Thermo Fisher, USA). N-terminal sequencing of rhIL-25 was performed by Shanghai Applied Protein Technology Co. Ltd.

\section{IL-25 interaction assay}

The binding ability of recombinant rhIL-25 to its conjugate IL-17RB (also IL-17BR) was tested by pull-down assay. Purified rhIL-25 was incubated with IL-17BR-Fc chimera (R\&D, USA) in fresh phosphate-buffered saline (PBS, $\mathrm{pH}$ 7.4) for $1 \mathrm{~h}$ at room temperature. The IL-17BR-Fc was pulled down by its Fc-tag using rProteinA Resin (GE Healthcare, USA). The beads were washed with PBS three times and then eluted with $0.1 \mathrm{M}$ glycine- $\mathrm{HCl}$ (pH3.0). A donkey anti-goat IgG (Santa Cruz, USA) was also used instead of IL-17BR-Fc as a negative control. 
In vitro biological activity assay

Biological activity was determined by adding rhIL-25 preparations to HEK293 cells or human lung fibroblast cell line HFL-I cells (Cat. GNHu43 and GNHu 5, respectively; Shanghai Cell Collection, SIBS, Shanghai, China) to assay G-CSF mRNA and protein expression level changes. The HEK293 cells were cultured at $2 \times 10^{5}$ cells per well in six-well plates (Corning, USA) in $2 \mathrm{ml}$ DMEM medium (Gibco, USA) containing $10 \%$ new-born calf serum (NCS) at $37{ }^{\circ} \mathrm{C}, 5 \% \mathrm{CO}_{2}$, while the HFLI cells were cultured at $1 \times 10^{5}$ cells per well in MEM $\alpha$ medium containing $10 \%$ heat-inactivated fetal bovine serum (FBS). Then, the cells were starved of serum for $24 \mathrm{~h}$. Purified rhIL-25 was diluted and added into a six-well plate $(2 \mathrm{ml} / \mathrm{well})$ in triplicate to reach concentrations of 50,100,200, and $400 \mathrm{ng} /$ $\mathrm{ml}$. After $24 \mathrm{~h}$ of incubation, the cells were lysed for RNA extraction using TRIzol reagent and operated according to manufacturer's instruction (Invitrogen). First-strand cDNA synthesis was performed using RevertAid First Strand cDNA synthesis kit (Invitrogen). The product of first-strand cDNA synthesis was used directly for real-time PCR assay. The primers used for G-CSF amplification were 5'-CAGTTAC AATGTGACAGTGGAGGG-3' and 5'-TTTGACTCC CGAACATCACCGAC-3', respectively. Commercially available recombinant hIL-25 derived from E. coli (R\&D, USA) was also used as control. The mRNA level of GAPDH was used as normalization control.

G-CSF production in cell culture supernatant was also assayed using a human G-CSF quantikine ELISA kit (R\&D). The cell culture and rhIL-25 treatment is the same as that for real-time PCR. After $24 \mathrm{~h}$ treatment with rhIL-25, the culture supernatant was collected for ELISA assay according the manufacturer's manual.

Hoechst staining and flow cytometric assay of apoptosis

Two breast cancer cell lines, HBL-100 (Cat. GNHu10, Shanghai Cell Collection, SIBS) and MDA-MB-231 (No. HTB-26, ATCC, USA), were seeded at a density of $1 \times 10^{5}$ cells per well in $0.5 \mathrm{ml}$ DMEM medium containing $10 \% \mathrm{NCS}$ in a 24-well plate (Corning, USA) and cultured to $80 \%$ saturation at $37{ }^{\circ} \mathrm{C}, 5 \% \mathrm{CO}_{2}$. After $12 \mathrm{~h}$ of serum starvation, cells were treated with rhIL-25 for 4 or $24 \mathrm{~h}$ at $37^{\circ} \mathrm{C}, 5 \% \mathrm{CO}_{2}$. At indicated time, cells were washed twice with PBS, then Hoechst 33342 solution (Invitrogen) was added at $1 \mu \mathrm{g} / \mathrm{ml}$, and incubated for $30 \mathrm{~min}$ at room temperature. Images were taken with a fluorescene microscope (IX71, Olympus, Japan).

Apoptotic cells were measured by annexin V-FITC/ propidium iodide (PI) staining and flow cytometry. Briefly, HBL-100 and MDA-MB-231 cells were seeded at a density of $4 \times 10^{5}$ cells per well in a six-well plate and cultured to $80 \%$ saturation at $37{ }^{\circ} \mathrm{C}, 5 \% \mathrm{CO}_{2}$. After $12 \mathrm{~h}$ of serum starvation, cells were treated with gradient concentration of rhIL-25 for $8 \mathrm{~h}$ at $37^{\circ} \mathrm{C}, 5 \% \mathrm{CO}_{2}$. After that, cells were harvested using citric acid, washed twice with cold PBS, and then resuspened in $500 \mu \mathrm{l}$ binding buffer. Afterward, $5 \mu \mathrm{l}$ annexin V-FITC and $5 \mu \mathrm{PI}$ (BD, USA) were added and incubated with cells for $15 \mathrm{~min}$ in the dark at room temperature and then analyzed on a flow cytometer (Epics Altra system, Beckmen-Coulter, USA; analysis software is EXPO32 V1.2 Analysis). Early apoptotic (lower right quadrant) and late apoptotic (upper right quadrant) cells were identified and expressed as percentage of cells.

GenBank accession numbers

The accession number of wild-type IL-25 is BC069565; the accession number of codon-optimized IL-25 is KF360054.

\section{Results}

Construction of the recombinant expression vector

The full-length of $h I L-25$ cDNA was $534 \mathrm{bp}$, encoding a polypeptide of 177 amino acid residues with a putative signal sequence and pre-peptide of 32 amino acid residues. The 438bp fragment coding for mature IL-25 proceeded for codon optimization based on P. pastoris preference for efficiency of rhIL-25 production. The sequence alignment result showed that the codon-optimized $I L-25$ shares $72 \%$ identity with the wild-type $I L-25$ after averaging the distribution of $\mathrm{G}+\mathrm{C}$ content and eliminating the potential hairpin structure. The substitute of nucleotides does not alter their coding amino acid sequences. DNA sequencing of the recombinant vector confirmed the accuracy of the reading frame of $I L-25$. The synthesized DNA was directly inserted into the open reading frame of $\alpha$-factor signal sequence of the P. pastoris expression vector pPICZ $\alpha \mathrm{A}$ under the regulation of $A O X 1$ promoter.

Transformation and screening of transformants at shaking flask level

The resulting vector, pPICZ $\alpha \mathrm{A}-\mathrm{r} h I L-25$, was transformed into P. pastoris by electroporation and plated on YPDS medium containing increasing concentrations of zeocin for the rapid screening of multi-copy transformants. The number of transformants decreased with the increase of antibiotic concentration after 3 days of incubation. Colony PCR screening of the positive recombinant was performed to confirm the integration of recombinant vector into the Pichia genome.

Then, positive colonies were cultured and induced to express the recombinant proteins according to the manufacturer's instruction. Transformants from YPDS plates in the presence of different concentrations of zeocin were selected for expression 
Fig. 1 Analysis of total proteins in culture medium of $P$. pastoris expressing rhIL-25. Supernatants were collected at the indicated time after induction by methanol. The samples were separated on $15 \%$ SDS-PAGE and stained with silver (a) or Coomassie brilliant blue (c, d). a Shake flask culture medium of $P$. pastoris strain X-33 transformed by wild hIL25. b Western blot analysis. c, d Fermentation culture supernatants of X-33 transformed by codon-optimized hIL 25 .

c Non-reduction, loading buffer without $\beta$-mercaptoethanol. d Reduction, loading buffer with $\beta$-mercaptoethanol a

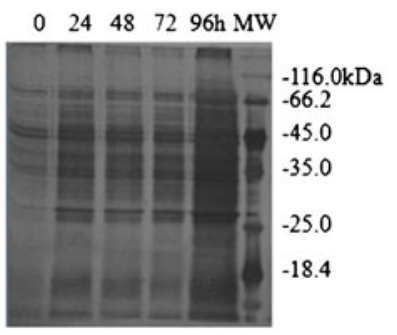

b

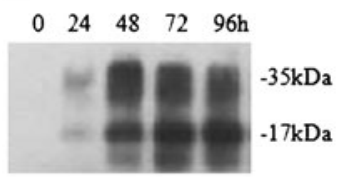

C

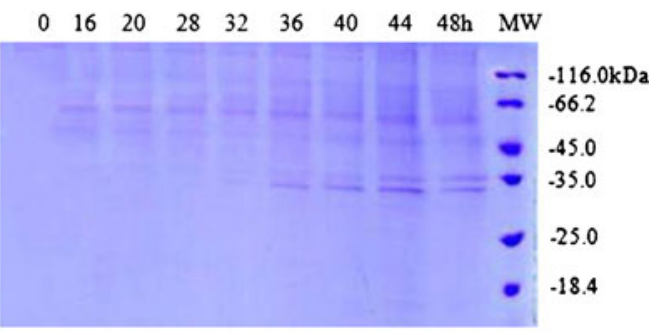

d

$\begin{array}{lllllllll}0 & 16 & 20 & 28 & 32 & 36 & 40 & 44 & 48 \mathrm{~h} \text { MW }\end{array}$ a

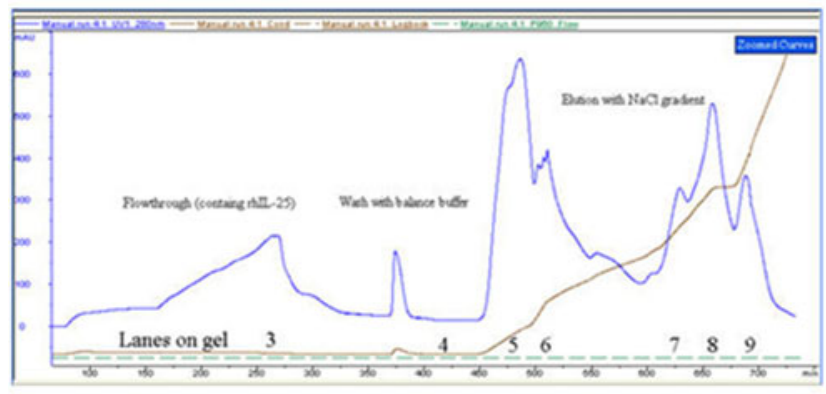

b

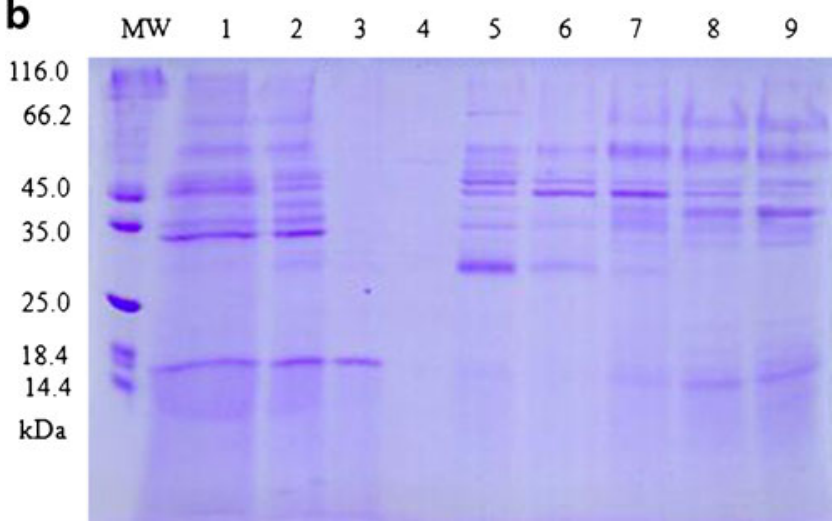

Fig. 2 Purification of rhIL-25 protein. a The fermentation supernatant was concentrated by ultrafiltration and then the buffer exchanged against $50 \mathrm{mM}$ Tris- $\mathrm{HCl}$ and $1 \mathrm{mM}$ EDTA, loaded onto Q sepharose Fast Flow resin, and eluted using $\mathrm{NaCl}$ gradient from 0 to $1 \mathrm{M}$. The rhIL-25 protein was flowing through the Q Sepharose FF, while the containments were bound by the column. b The fractions were separated on $15 \%$ SDSPAGE. Lane $M$ molecular weight marker. Lane 1 fermentation supernatant at $44 \mathrm{~h}$ after methanol induction. Lane 2 after buffer exchange. Lane 3 flow-through of Q FF. Lane 4 wash-off using balance buffer. Lane 5-9 eluate from Q Sepharose FF

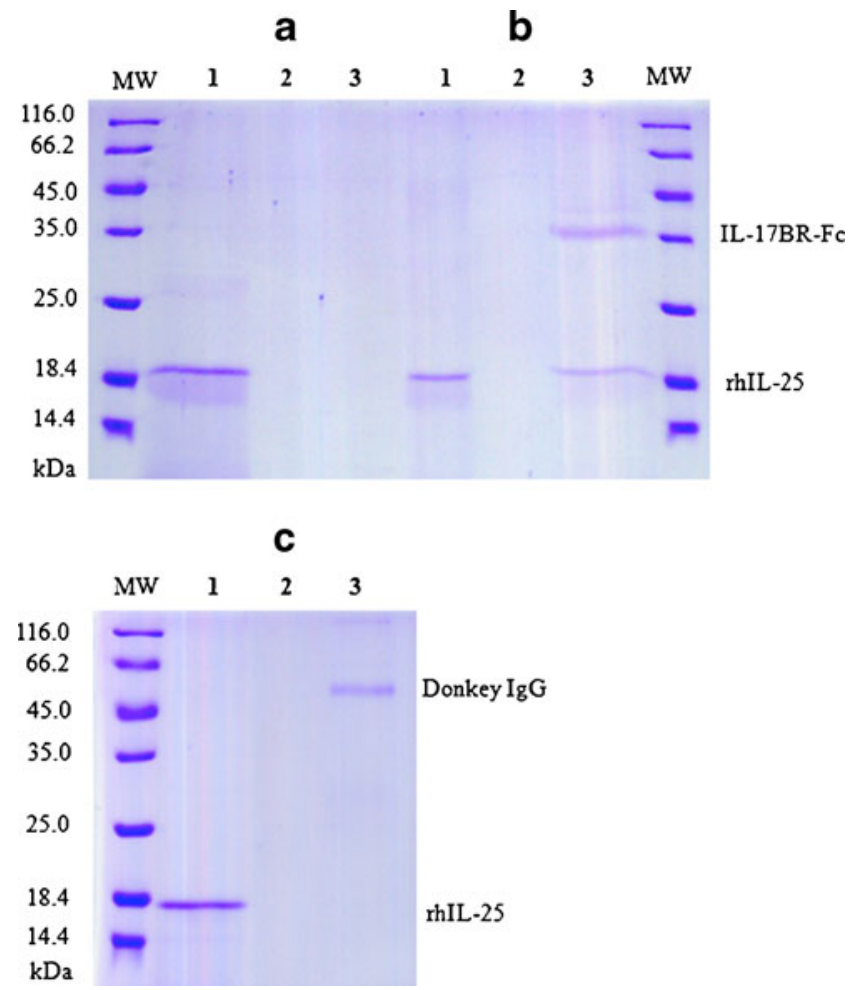

Fig. 3 IL-17BR binding assay. Purified rhIL-25 was evaluated by its capacity to interact with IL-17BR. Recombinant hIL-25 was incubated with IL-17BR-Fc chimera and then pulled down with rProtein A resin which specifically binds the Fc-tag on IL-17BR-Fc chimera. Donkey anti-goat IgG was used as a negative control for non-specific binding. Bound proteins were analyzed by SDS-PAGE and Coomassie staining. Lanes represent flow-through (1), wash (2), and elution fractions (3) from the resin using a rhIL-25 only, b rhIL-25 incubated with IL-17BRFc chimera, and $\mathbf{c}$ rhIL-25 incubated with donkey anti-goat IgG 
screening. SDS-PAGE and western blot analysis showed that rhIL-25 was successfully expressed in the culture medium of $P$. pastoris X-33 transformants. Secreted rhIL-25 from wild-type hIL-25 transformants could be detected in silver-stained gel, while it could be clearly identified with Coomassie blue staining in codon-optimized transformants (shown in Fig. 1). The product demonstrated as a 17 - and a $34-\mathrm{kDa}$ band; both bands were identified by western blot using a mouse anti-hIL-25 monoclonal antibody. The $34-\mathrm{kDa}$ band was considered to be a homodimer form of the 17-kDa hIL-25. SDS-PAGE also showed a progressive accumulation of the rhIL-25, starting at $24 \mathrm{~h}$ post-induction, and reached the peak at $96 \mathrm{~h}$. Prolonged
Fig. 4 IL-25 induces G-CSF production. a, b IL-25 stimulates G-CSF mRNA expression in HFL-1 and HEK293 cells. The cells were treated with IL-25 and the mRNA expression level of G-CSF was examined by realtime RT-PCR. GAPDH mRNA levels were used as normalization controls. The data are presented as the fold increase after IL-25 induction compared with medium only (no IL-25 treatment) cell. c IL-25 induces the production of G-CSF protein, HFL-1 cells were treated with IL-25 in increased concentration for $24 \mathrm{~h}$, and G-CSF levels in the culture medium were measured by ELISA

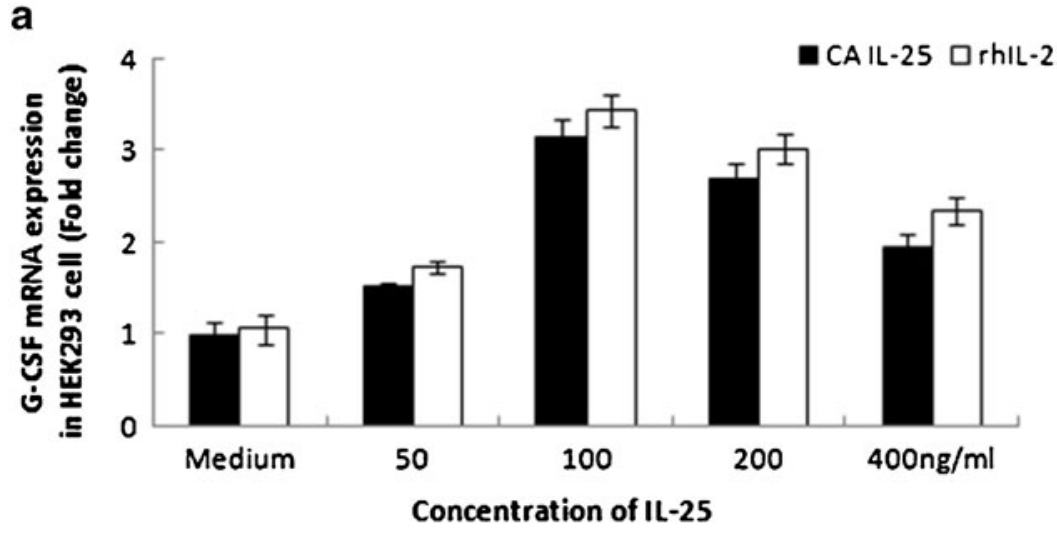

b
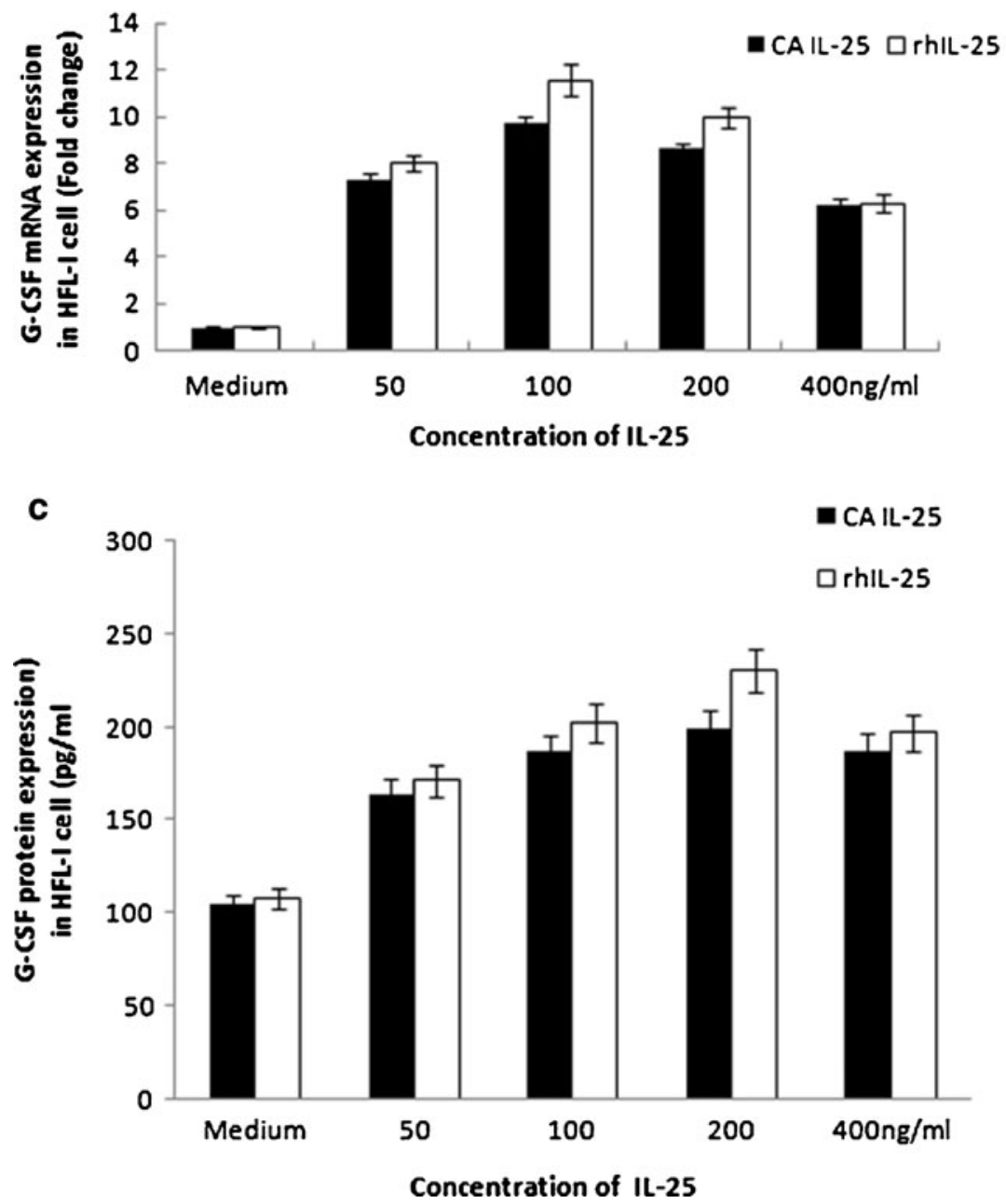
induction could not increase the amount of total rhIL-25 in the culture supernatant.

Large-scale expression and purification of rhIL-25

One of the transformants with highest expression was grown on a 5-1 bioreactor and induced with methanol for $48 \mathrm{~h}$. Culture medium was collected and centrifuged to generate supernatant every $4 \mathrm{~h}$. The recombinant protein expression started $16 \mathrm{~h}$ after methanol induction and reached the peak at $44 \mathrm{~h}$ (shown in Fig. 1). At the end of fermentation, the wet weight of yeast reached $260 \mathrm{~g}$ per liter of broth volume, while the volume of supernatant increased to $2.6 \mathrm{~L}$. The rhIL-25 in culture supernatant was estimated to be $100 \mathrm{mg} / \mathrm{l}$ based on SDS-PAGE results. The culture supernatant was collected and concentrated using membrane ultrafiltration. Subsequently, rhIL-25 was allowed to pass through the Q sepharose Fast Flow column, while most of the contaminants were absorbed (Shown in Fig. 2). The rhIL-25 was further polished through high-resolution gel filtration to remove trace impurities. Finally, we got $39.6 \mathrm{mg}$ purified rhIL-25 per liter of culture supernatant in monomer form.

$\mathrm{N}$-terminal sequencing result indicated that the five amino acid residues at the N-terminal of the rhIL-25 were YSHWP, which matched with that of the deduced mature IL-25.

Functional characterization and bioactivity assay of rhIL-25

The functionality of rhIL-25 was evaluated by testing its capacity to bind IL-17BR using a pull-down assay. As shown in Fig. 3, we detected the specific interaction of the purified recombinant rhIL-25 with IL-17BR-Fc chimera. The rProteinA affinity gel was also used alone in this assay for it non-specifically binds to rhIL-25. The biological activity of rhIL-25 was detected by its ability to directly stimulate G-CSF production from two cell lines in vitro. As shown in Fig. 4, rhIL-25 stimulated G-CSF mRNA expression in both HEK293 and HFL-1 cells, with higher expression in HFL-1 cell. G-CSF protein production from HFL-1 cells was confirmed by ELISA. The activity of the purified rhIL-25 was comparable with the commercially available recombinant hIL-25.

Recombinant hIL-25 induces apoptosis in breast cancer cells by annexin V-FITC/PI staining assay

To investigate whether apoptosis occurs in rhIL-25-treated breast cancer cells, we performed a Hoechst33342 staining assay to detect apoptosis-induced chromosome fragmentation. Hoechst33342 staining was used to visualize the nuclear morphology following rhIL-25 treatment (shown in Fig. 5). Fluorescent signals were detected in nucleic regions of cells

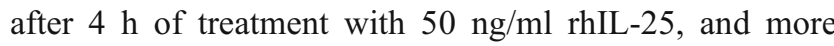
obviously, morphologic changes of apoptosis such as condensed chromatin and shrunken nucleus were detected after $24 \mathrm{~h}$ of treatment.

To confirm the various stages of apoptosis or necrosis, MDA-MB-231 and HBL-100 cells were treated with the indicated concentrations of rhIL-25 for $8 \mathrm{~h}$, followed with annexin V-FITC/PI staining and FACS analysis. Figure 6 shows a dotplot display produced from annexin V-FITC/PI with flow cytometry. After the administration of rhIL-25 for $8 \mathrm{~h}$, apoptosis was induced in both cells in a dose-dependent manner.

\section{Discussion}

The aim of the current work was to produce a large amount of soluble and bioactive rhIL-25 suitable for biological studies with less cost and no denaturing agents or refolding steps
Fig. 5 Fluorescence photomicrographs of two breast cancer cells with Hoechst 33242 staining after rhIL-25 treatment. a-c HBL-100 cells. d-f, MDAMB-231 cells. a, d Untreated with rhIL-25. b, e, At $4 \mathrm{~h}$ after treatment with $50 \mathrm{ng} / \mathrm{ml}$ rhIL-25. c, f At $24 \mathrm{~h}$ after treatment with $50 \mathrm{ng} / \mathrm{ml} \mathrm{rhIL}-25 . \times 400$ magnification
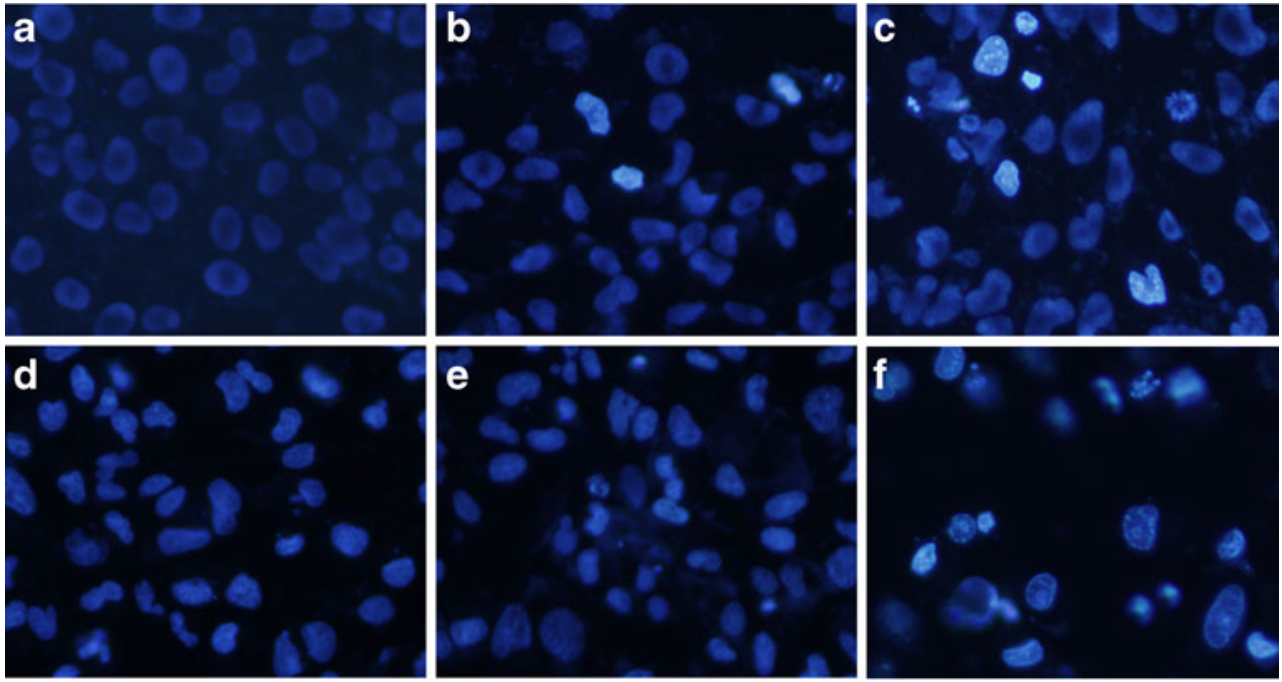
Fig. 6 Cell apoptosis was induced with rhIL-25. After $8 \mathrm{~h}$ of treatment of rhIL-25 with indicated dosages, HBL-100 and MDA-MB-231 cells were harvested and stained with annexin V-fluorescein and PI. Percentage of annexin-V/PI stained cells was determined by flow cytometry
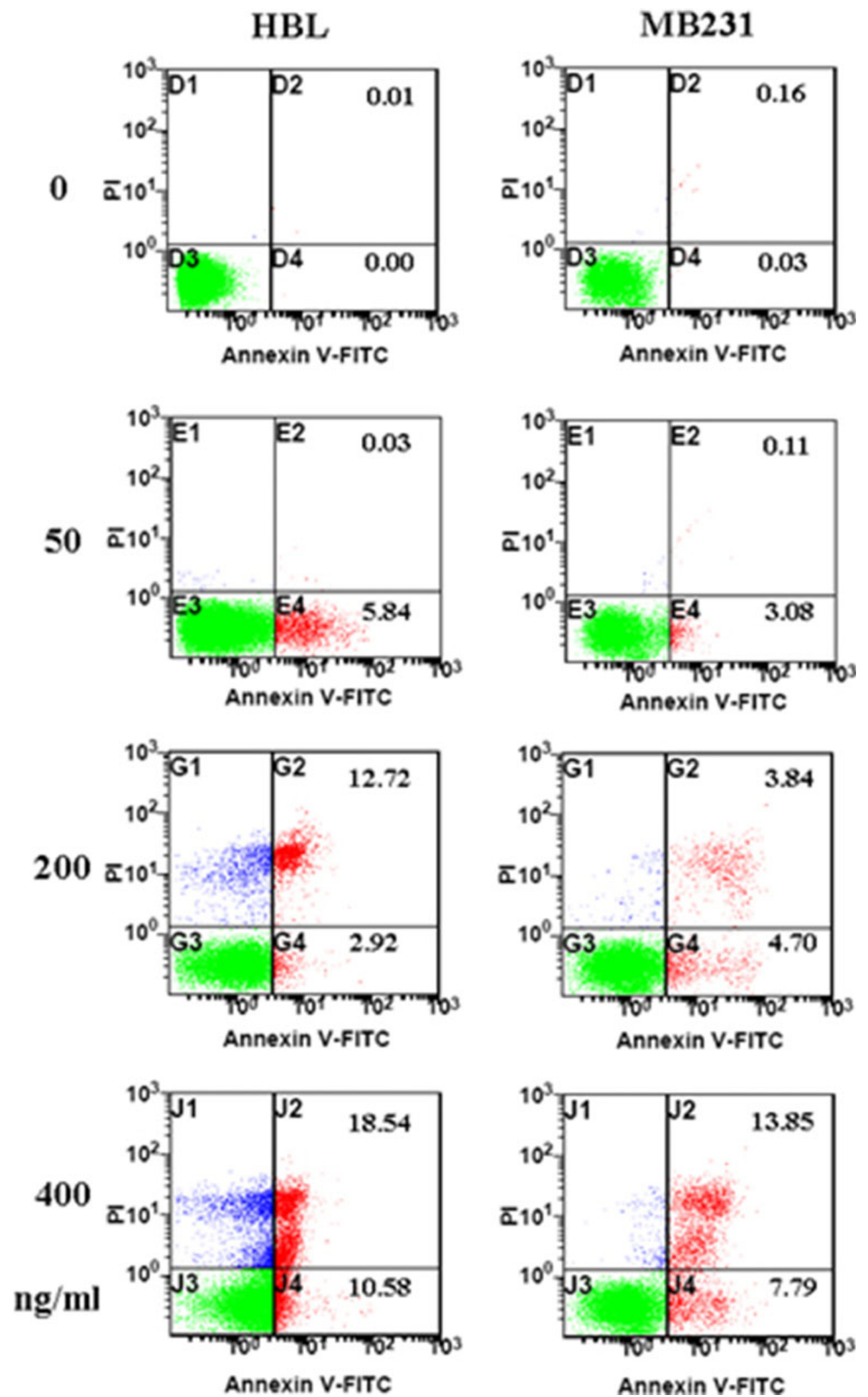

Annexin V-FITC present in the $E$. coli expression system. Human IL-25 has been produced transiently in human 293 cells using recombinant adenovirus or Sf9 insect cells (Fort et al. 2001; Hurst et al. 2002), while the productivity of the recombinant protein was 
unknown. It was also produced as inclusion bodies in E. coli, which need denaturing and refolding steps (unpublished data in this laboratory).

Yeasts, particularly the methylotrophic yeast $P$. pastoris, have numerous advantages as a host system for the production of recombinant heterologous proteins. They are much easier to perform and cheaper in cost compared with that of bacterial expression systems. At the same time, P. pastoris, as a eukaryote, thereby provides the potential for producing soluble recombinant proteins with correct folding and post-translational modifications (Cregg et al. 2009; Damasceno et al. 2012).

To obtain the high-quality and extracellular expression of rhIL-25, we chose pPICZ $\alpha \mathrm{A}$ as the expression vector and $P$. pastoris $\mathrm{X}-33$ as the host strain. Many proteins produced in $P$. pastoris are similar to those produced in mammalian cells based on synthesis, structure, and bioactivity. The expression vector $\mathrm{pPICZ} \alpha \mathrm{A}$ has an $\alpha$-factor secretion signal sequence, which has been used with great success. However, although the rhIL-25 was presently secreted in P. pastoris, the low secretion level using a wild-type gene restricted its yield, as shown in Fig. 1a, b; rhIL-25 can hardly be discriminated using silver staining. There are many factors that markedly influence the expression of foreign genes, including $P$. pastoris codon bias, base content of foreign genes, transcriptional and translational blocks, and secondary structure of mRNA (Cregg et al. 2009; Woo et al. 2002). To increase the secretion expression level, we optimized the gene of interest by means of substituting rare codons with $P$. pichia preferable triplets. At the same time, we balanced the $\mathrm{G}+\mathrm{C}$ content, removed the $\mathrm{A} /$ $\mathrm{T}$ or $\mathrm{G} / \mathrm{C}$ repeats, and avoided the formation of hairpin or special secondary structure of $h I L-25$ mRNA(Li et al. 2008). The productivity of rhIL-25 was much higher using codon optimized rhIL-25.

The function of rhIL-25 was verified by its binding capability with IL-17RB. The biological activity of rhIL-25 was confirmed by its ability to induce G-CSF production in pulmonary fibroblasts HFL-1 and renal epithelium cell HEK293, which is consistent with published results (Pan et al. 2001). We also tried some breast cancer cell lines to detect whether they can produce G-CSF after rhIL-25 treatment. We found that more dominantly rhIL-25 can induce the death rate of breast cell. Apoptosis-induced chromosome fragmentation was detected using Hoechst33342 staining. Annexin VFITC/PI staining assay indicated that rhIL-25 induced apoptosis in breast cancer cell MDA-MB-231 and HBL-100, which was in agreement with Furuta's report that IL-25 causes apoptosis of some breast cancer cells (Furuta et al. 2011).

As observed by non-reduced and reduced SDS-PAGE, The rhIL-25 produced by $P$. pastoris was mainly homodimers, which is in agreement with the finding that IL-17s adopt a cystine knot fold (Hymowitz et al. 2001). IL-17A had also been expressed in $P$. pastoris as both monomer and homodimer forms (Murphy et al. 1998). IL-25 has 11 cysteines in total, more than that of IL-17A and other members in IL-17 family, which indicate its unique character. The exact disulfide bonds within polypeptide or between peptide chains need further study. In this study, although the homodimer form of rhIL-25 was shown in culture medium, the monomer form was the unique form after purification. The method of purification also indicated rhIL-25 having a distinctive structure. The bond in the homodimer is probably a weak disulfide bonds. To learn the distinct biological activity of this cytokine, further work is needed to assess the manner of dimerizing and the importance of inter-peptide disulfide bonds forming.

In conclusion, we have described a highly efficient way of producing large quantities of functional rhIL-25 using a $P$. pastoris expression system. This system may facilitate further studies of its structure-function relationship in the near future.

Acknowledgments We thank Prof. Houyan Song for insightful comments and valuable discussions. We thank Yuxiong Wang and Yongjiang Lang for expert technical assistance. This research was supported by "The Key Program of New Drug Innovation", Ministry of Science and Technology (20092X09503-006).

Conflict of interest The authors declare that they have no conflict of interest.

Open Access This article is distributed under the terms of the Creative Commons Attribution License which permits any use, distribution, and reproduction in any medium, provided the original author(s) and the source are credited.

\section{References}

Angkasekwinai P, Park H, Wang YH, Wang YH, Chang SH, Corry DB, Liu YJ, Zhu Z, Dong C (2007) Interleukin 25 promotes the initiation of proallergic type 2 responses. J Exp Med 204:1509-1517

Benatar T, Cao MY, Lee Y, Li H, Feng N, Gu X, Lee V, Jin H, Wang M, Der S, Lightfoot J, Wright JA, Young AH (2008) Virulizin induces production of IL-17E to enhance antitumor activity by recruitment of eosinophils into tumors. Cancer Immunol Immunother 57:17571769

Benatar T, Cao MY, Lee Y, Lightfoot J, Feng N, Gu X, Lee V, Jin H, Wang M, Wright JA, Young AH (2010) IL-17E, a proinflammatory cytokine, has antitumor efficacy against several tumor types in vivo. Cancer Immunol Immunother 59:805-817

Cregg JM, Tolstorukov I, Kusari A, Sunga J, Madden K, Chappell T (2009) Expression in the yeast Pichia pastoris. Methods Enzymol 463:169-189

Damasceno LM, Huang CJ, Batt CA (2012) Protein secretion in Pichia pastoris and advances in protein production. Appl Microbiol Biotechnol 93:31-39

Dolgachev V, Petersen BC, Budelsky AL, Berlin AA, Lukacs NW (2009) Pulmonary IL-17E (IL-25) production and IL-17RB(+) myeloid cell-derived Th2 cytokine production are dependent upon stem cell factor-induced responses during chronic allergic pulmonary disease. J Immunol 183:5705-5715

Fort MM, Cheung J, Yen D, Li J, Zurawski SM, Lo S, Menon S, Clifford T, Hunte B, Lesley R, Muchamuel T, Hurst SD, Zurawski G, Leach MW, Gorman DM, Rennick DM (2001) IL-25 induces IL-4, IL-5, and IL-13 and Th2-associated pathologies in vivo. Immunity 15:985-995 
Furuta S, Jeng YM, Zhou L, Huang L, Kuhn I, Bissell MJ, Lee WH (2011) IL-25 causes apoptosis of IL-25R-expressing breast cancer cells without toxicity to nonmalignant cells. Sci Transl Med 3:78ra31

Hurst SD, Muchamuel T, Gorman DM, Gilbert JM, Clifford T, Kwan S, Menon S, Seymour B, Jackson C, Kung TT, Brieland JK, Zurawski SM, Chapman RW, Zurawski G, Coffman RL (2002) New IL-17 family members promote $\mathrm{Th} 1$ or $\mathrm{Th} 2$ responses in the lung: in vivo function of the novel cytokine IL-25. J Immunol 169:443-453

Hymowitz SG, Filvaroff EH, Yin JP, Lee J, Cai L, Risser P, Maruoka M, Mao W, Foster J, Kelley RF, Pan G, Gurney AL, de Vos AM, Starovasnik MA (2001) IL-17s adopt a cystine knot fold: structure and activity of a novel cytokine, IL-17F, and implications for receptor binding. EMBO J 20:5332-5341

Ikeda K, Nakajima H, Suzuki K, Kagami S, Hirose K, Suto A, Saito Y, Iwamoto I (2003) Mast cells produce interleukin-25 upon Fc epsilon RI-mediated activation. Blood 101:3594-3596

Kang CM, Jang AS, Ahn MH, Shin JA, Kim JH, Choi YS, Rhim TY, Park CS (2005) Interleukin-25 and interleukin-13 production by alveolar macrophages in response to particles. Am J Respir Cell Mol Biol 33:290-296

Lee J, Ho WH, Maruoka M, Corpuz RT, Baldwin DT, Foster JS, Goddard AD, Yansura DG, Vandlen RL, Wood WI, Gurney AL (2001) IL$17 \mathrm{E}$, a novel proinflammatory ligand for the IL-17 receptor homolog IL-17Rh1. J Biol Chem 276:1660-1664

Li Z, Hong G, Wu Z, Hu B, Xu J, Li L (2008) Optimization of the expression of hepatitis B virus e gene in Pichia pastoris and immunological characterization of the product. J Biotechnol 138:1-8

Mchenga SS, Wang D, Li C, Shan F, Lu C (2008) Inhibitory effect of recombinant IL-25 on the development of dextran sulfate sodiuminduced experimental colitis in mice. Cell Mol Immunol 5:425-431

Monteleone G, Pallone F, MacDonald TT (2010) Interleukin-25: a twoedged sword in the control of immune-inflammatory responses. Cytokine Growth Factor Rev 21:471-475

Murphy KJ, Gagne P, Pazmany C, Moody MD (1998) Expression of human interleukin-17 in Pichia pastoris: purification and characterization. Protein Expr Purif 12:208-214

Pan G, French D, Mao W, Maruoka M, Risser P, Lee J, Foster J, Aggarwal S, Nicholes K, Guillet S, Schow P, Gurney AL (2001) Forced expression of murine IL-17E induces growth retardation, jaundice, a Th2-biased response, and multiorgan inflammation in mice. J Immunol 167:6559-6567

Rickel EA, Siegel LA, Yoon BR, Rottman JB, Kugler DG, Swart DA, Anders PM, Tocker JE, Comeau MR, Budelsky AL (2008) Identification of functional roles for both IL-17RB and IL-17RA in mediating IL-25-induced activities. J Immunol 181:4299-4310

Shi Y, Ullrich SJ, Zhang J, Connolly K, Grzegorzewski KJ, Barber MC, Wang W, Wathen K, Hodge V, Fisher CL, Olsen H, Ruben SM, Knyazev I, Cho YH, Kao V, Wilkinson KA, Carrell JA, Ebner R (2000) A novel cytokine receptor-ligand pair. Identification, molecular characterization, and in vivo immunomodulatory activity. J Biol Chem 275:19167-19176

Sonobe Y, Takeuchi H, Kataoka K, Li H, Jin S, Mimuro M, Hashizume Y, Sano Y, Kanda T, Mizuno T, Suzumura A (2009) Interleukin-25 expressed by brain capillary endothelial cells maintains blood-brain barrier function in a protein kinase $\mathrm{C}$ epsilon-dependent manner. $\mathrm{J}$ Biol Chem 284:31834-31842

Tian E, Sawyer JR, Largaespada DA, Jenkins NA, Copeland NG, Jr Shaughnessy JD (2000) Evi27 encodes a novel membrane protein with homology to the IL17 receptor. Oncogene 19:2098-2109

Wang YH, Angkasekwinai P, Lu N, Voo KS, Arima K, Hanabuchi S, Hippe A, Corrigan CJ, Dong C, Homey B, Yao Z, Ying S, Huston DP, Liu YJ (2007) IL-25 augments type 2 immune responses by enhancing the expansion and functions of TSLP-DC-activated Th2 memory cells. J Exp Med 204:1837-1847

Woo JH, Liu YY, Mathias A, Stavrou S, Wang Z, Thompson J, Jr Neville DM (2002) Gene optimization is necessary to express a bivalent anti-human anti-T cell immunotoxin in Pichia pastoris. Protein Expr Purif 25:270-282

Xiong AS, Yao QH, Peng RH, Li X, Fan HQ, Cheng ZM, Li Y (2004) A simple, rapid, high-fidelity and cost-effective PCR-based twostep DNA synthesis method for long gene sequences. Nucleic Acids Res 32:e98

Zaph C, Du Y, Saenz SA, Nair MG, Perrigoue JG, Taylor BC, Troy AE, Kobuley DE, Kastelein RA, Cua DJ, Yu Y, Artis D (2008) Commensal-dependent expression of IL-25 regulates the IL-23-IL17 axis in the intestine. J Exp Med 205:2191-2198 